Original Contribution

\title{
INFLUENCE OF CHILDREN IN REAL ESTATE FAMILY PURCHASE DECISION-MAKING CONTEXT
}

\author{
I. Kancheva* \\ International Economics Relations Department, University of Economics, Varna, Bulgaria
}

\begin{abstract}
Purpose: Children play a significant role as active participants in different markets through their own spending power. They are also able to exert considerable influence - explicit or implicit - over other family members' consumer behavior. The combination of various spatial, structural, financial and practical aspects place the purchase of a real estate among the most complex for the family. The objective of the present paper is to reveal the degree and form of children's influence throughout family real estate purchase decision-making process.

Methods: This paper represents the results of an empirical study focused on parental perceptions of children's influence in a family real estate purchase. Data were gathered using a convenience sample of 286 respondents - 156 men and 130 women from different Bulgarian families. Frequency distributions, analysis of variance, paired samples and independent samples t-test were applied for the aims of the analysis.

Results: Children are found to exert moderate indirect influence throughout the family real estate purchase. They are most influential in the final phase of the real estate purchase decision-making process. Although high influence scores are detected in some attributive decisions, children are found least influential over choices related to technical and financial aspects of the purchase.
\end{abstract}

Key words: Consumer behavior, Family economics, Buying decisions, Real property purchase

\section{INTRODUCTION}

Real estate purchase in family context is among the most complicated and important tasks for this closely-related group of people. The nature of the real property as "a bundle of attributes" (1) requires expertize on a diversity of real estate attributes. Furthermore, there is a special emotional connection between a family and its real estate. People are not buying a couple of walls and a roof above but a home or a place for recreation where to raise their children and create memories, or at least, an investment to ensure the future of their offspring.

A real estate purchase entails coordination between often opposing needs and preferences of separate individuals. Family members have different influence, described by their ability to

\footnotetext{
*Correspondence to: Address: University of Economics - Varna, 77 Knyaz Boris I Blvd., Varna 9002, Bulgaria, phone number: 0887312771, email: irina_kancheva@abv.bg
}

affect the behavior, feelings and attitudes of others in order to reach the desired outcome. There are two basic types - direct influence, expressed by explicit actions and indirect, represented by personal needs taken into account by the decision-makers.

Despite the evolution in the family needs associated with their birth and growing up (2), children have rarely become a focus in family consumer behavior research. Even though young members are consumers of plenty of goods acquired by the family, the role they play in family decisions is often underestimated because of limited resources they contribute to a family purchase.

Empirical studies including children in the set of decision-making agents in the family examine family decision-making behavior in the context of different product categories food and toys (3), groceries (4-5), TV programs (6), family vacation (7-8). The influence of children varies across product categories (9-11). They are more influential 
over the choices of products for their own consumption. On the contrary, in the case of major family purchases associated with relatively high price and financial risk (car, home appliances, family computer, TV, life insurance and financial products, etc.) the influencing power of children is limited by their parents. Lee and Levi (12) outline their indirect influence during the process of family real estate purchase decision making. It is illustrated mainly by the specific needs of the young family members considered by their parents in the process of outlining the characteristics of the property searched and evaluation of different alternatives.

Children's influence changes between the phases of family decision-making process (9). Highest influence is detected in the problem recognition stage (13-14) and in the choices of expressive product characteristics like design, color and trademark $(18-19,21)$. On the opposite, they are found considerably less influential in the final decision stage (14-18) and sub-decisions determining financial (18$19)$ and spatial frames of the purchase $(9,19-$ 20). Possible explanations of this influence distribution can be found in scarce information, experience and capital resources possessed by children (13). In previous research children's influence is related to the income level and social class of the family (2223). Young members of lower income and lower social class families are found less influential compared to their wealthier peers. Recent research (24-25) show no significant differences based on the social and income level, or to parental educational degrees.

\section{METHODS}

This paper is an extension of previous research in the field of family real estate purchase consumer behavior (26). Data was collected between September and December 2018. A convenience sampling technique was applied in the research design. The study was directed towards men and women from Bulgarian married and cohabiting couples meeting the requirements to have at least one child and to have bought a real estate not more than 5 years before the survey period.

Respondents were first asked to assess the type of impact their children have over the family real estate purchase as lack of influence, indirect or direct influence. Further, parents were requested to determine the influence exercised by children throughout the decision-making process.
In order to cover a wider family purchase decision-making picture three widely accepted approaches were combined. As a result, a threestage decision-making process including problem identification, information search and final decision phases (27-29) was enriched with subdecisions (30-31) and real estate attribute choices (32-33). Three sub-decisions regarding the choices of moment, retailer and purchase budget limitations were adopted from the popular subdecision approach but brand related choice was omitted because it is considerate inadequate to this product category. Twelve real estate attributes were applied to cover instrumental, expressive and financially-juridical characteristics of the property. A five-point scale was used to measure the overall degree of children's influence over the family real estate purchase, along with their part in separate stages, sub-decisions and choices of attributes, indicating: 1 - No influence; 2 - Slight influence; 3 - Moderate influence; 4 - High influence; 5 Absolute influence.

\section{RESULTS AND DISCUSSION}

The sample includes the answers of 286 respondents -156 men and 130 women. $1 \%$ of them are middle aged - between 30 and 59 years old. $18 \%$ of them are up to 29 years old, while only 1 man and 1 woman are over 60 years old. $76 \%$ of the sample are married while $24 \%$ of them are partners in cohabiting couples. Nearly a quarter of the respondents have been living with their spouse for under 5 years, the majority $58 \%$ - for between 6 and 19 years and the remaining $19 \%$ - for more than 20 years. $72 \%$ of the respondents have graduated higher education, $21 \%$ of them are with secondary education. $64 \%$ of the sample have one only child living in the family, $32 \%-2$ children and $4 \%-3$ children. Parents of children below 7 years-old are prevalent in the sample. Kids over 18 who have graduated high school are living in $13 \%$ of the families.

As a part of the family, children are expected to be active users of the property purchased. Although parental perceptions vary, the majority of the sample $(91 \%)$ report children's indirect influence in this purchase. This means that mothers and fathers have considered the needs of their offspring without delegating them real decision-making power during this process. $5 \%$ of the sample report complete lack of influence of their children over a residential real estate family purchase. Direct participation of children is reported by $4 \%$ of the respondents. The proportions of children's influence responses are depicted in Figure 1. 


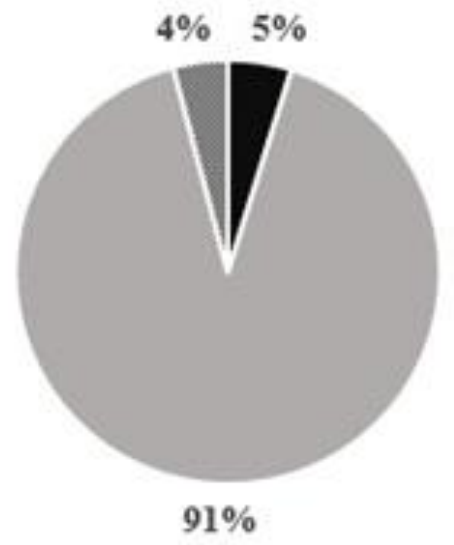

- no influence $=$ indirect influence $=$ direct influence

Figure 1. Type of children's overall influence

Respondents report a moderate overall influence of children in a residential real estate purchase.

Relative frequency distributions of parental perceptions of children's influence over the decision-making phases and sub-decisions are presented in Figure 2. Results show that they are most influential at the final stage of the family decision-making process while they affect very slightly the information search phase. Paired samples t-test results show significantly lower parental perceptions of children's influence in the first two stages of the decision-making process compared to the final phase. This finding contradicts with the majority of previous research in which children are reported most powerful in the initial stage of the process. However, it supports Lee and Beatty's (34) conclusion that young family members have the strongest influence on the final decision stage.

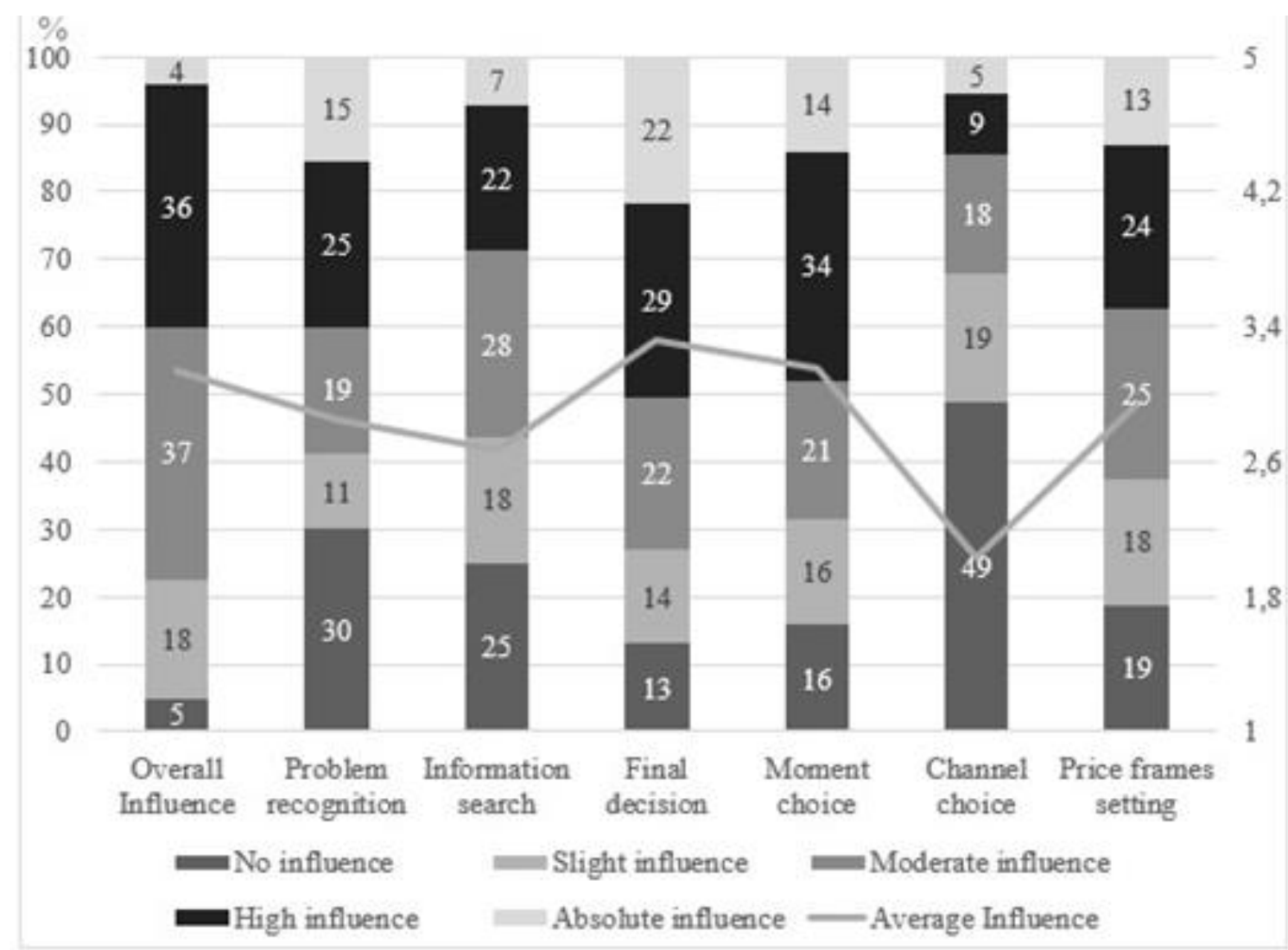

Figure 2. Parental perceptions of children's influence - decision-making stages and sub-decisions 
As far as decision-making sub-stages are concerned, children in the family are found least influential in the retailer choice. Almost half of the respondents - 49\% - state that their children have no influence at all over this decision. Specialized knowledge of market trends and options available is necessary for the choice of real estate distribution channel and children are usually not expected to be well informed in this area. This sub-decision is highly connected to additional expenses emerging in respect to this purchase. Although both other sub-decisions fall into the moderate influence segment, children are reported less influential in financial frames settings subdecision. These results are, probably, not a surprise, considering the restricted financial resources available to children and their
KANCHEVA I.

limited ability to support the family budget. The needs and schedule of children in the family are taken into account when making the moment for the purchase choice. Paired samples t-test results show statistically significant differences between the three subdecisions. These results, in the case of a real estate family purchase, adhere with previous findings concerning other product categories.

Relative frequency distributions and average scores of children's influence reported by parents over separate real estate characteristics' choices are illustrated in Figure 3. Children's influence over the choices of real estate attributes shows higher scores compared to the stages and subdecisions.

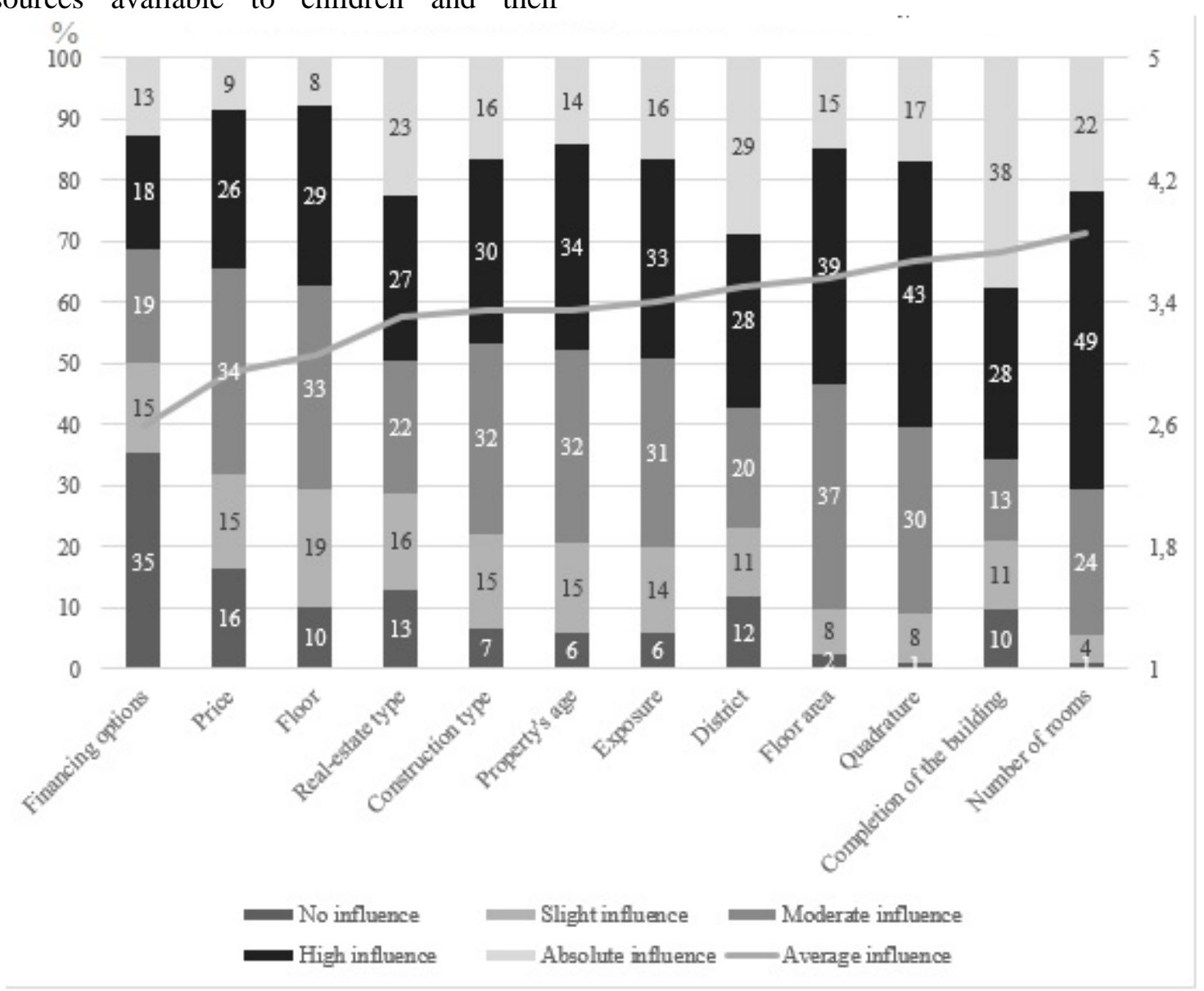

Figure 3. Parental perceptions of children's influence - real estate attributes

The highest influence is reported in the choices of characteristics directly connected to the potential of the real property to satisfy all family members' needs. Results, locating three out of four expressive characteristics - the number of rooms, district and exposure - in the high children's influence segment, support previous findings. However, high children's influence over the instrumental attributes floor area and quadrature, and the legally related completion of the building disagree with earlier research. These results emphasize the specific nature of the real estate product category. The number of rooms is connected to the opportunities for personal place and privacy for the family members. Exposure is linked to the daily quantity of sunlight and the atmosphere which can be created within the property. The choice of district is closely related to the presence of infrastructure 
KANCHEVA I.

necessary for the convenience of the family. Completion of the building is related to time frames, additional work and expenses necessary for the family to start the exploitation of their new real estate. This characteristic implies risks connected to delay or even termination of construction works which might result in considerable losses for the buyer. Quadrature and usable floor area determine the convenience of use and opportunities for enough space for both parents and children within their new home or holiday house. Instrumental characteristics like construction type and age of the property are influenced by children to a lower extent. Children in the family affect slightly financially related decision on the price of the real property and the use of credit instruments. More than $1 / 3$ of the respondents report complete lack of children's participation in the financing options choice. The influence of young family members diminishes over these choices because they are connected to long term investment goals and opportunities. These are often dependent on external parties like financial institutions.

Independent samples t-test and ANOVA are used for investigation of the effects of different factors on respondents' perceptions of children's influence. Table $\mathbf{1}$ exposes statistically significant results.
No statistically significant differences in the children's overall influence parental perceptions are found based on the characteristics gender, age, marital status, marriage and cohabitation duration, education, income level, number of children in the family and their age, as well as the reason for the purchase and previous experience available. Significant variation between male and female perceptions is found only in the problem recognition phase. Mothers in the sample evaluate the impact of their children higher compared to fathers in this stage of the decision-making process. Respondents' age is connected to statistically significant differences in the perceptions of children's influence in the choices of the attributes number of rooms and quadrature. In both cases, younger respondents - below 29 yearsold, evaluate their children's influence higher than the older parents in the sample. Considerable differences in respondents' perceptions, based on marital status, are detected in the problem recognition phase, moment choice sub-decision and the choice of the attribute price. Spouses in marital couples report higher children's influence in the initial stage of the decision-making process, time frames setting and when evaluating the cost of the real property, compared to partners in cohabiting couples.

Table 1. Statistically significant ANOVA and independent samples t-test results

\begin{tabular}{|c|c|c|c|c|c|}
\hline & & Factor & $\mathbf{t} / \mathbf{F}$ & $\mathbf{p}$ & Eta2 \\
\hline \multirow{8}{*}{ 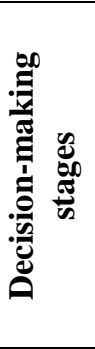 } & \multirow{3}{*}{ Problem recognition } & Gender & $-8,41$ & 0,00 & 0,20 \\
\hline & & Marital status & 2,25 & 0,03 & 0,02 \\
\hline & & Reason for purchase & 17,21 & 0,00 & 0,11 \\
\hline & \multirow{2}{*}{ Information search } & Marriage duration & 3,56 & 0,03 & 0,02 \\
\hline & & Age of children & 2,22 & 0,03 & 0,02 \\
\hline & \multirow{3}{*}{ Final decision } & Age of children & 3,75 & 0,00 & 0,05 \\
\hline & & Marriage duration & 5,36 & 0,05 & 0,04 \\
\hline & & Cohabitation & 3,97 & 0,02 & 0,03 \\
\hline \multirow{4}{*}{ के } & Moment Choice & Marital status & 2,10 & 0,04 & 0,02 \\
\hline & Channel Choice & Marriage duration & 5,14 & 0,01 & 0,04 \\
\hline & Price Frames & Age of children & 2,86 & 0,00 & 0,03 \\
\hline & Price Frames & Marriage duration & 3,03 & 0,05 & 0,02 \\
\hline \multirow{7}{*}{ 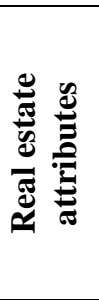 } & Number of rooms & Age of respondent & 4,08 & 0,00 & 0,06 \\
\hline & Quadrature & Age of respondent & 2,44 & 0,02 & 0,02 \\
\hline & \begin{tabular}{|l|} 
District \\
\end{tabular} & Reason & 5,08 & 0,01 & 0,03 \\
\hline & Exposure & Marriage duration & 3,54 & 0,03 & 0,02 \\
\hline & Floor & Marriage duration & 3,18 & 0,04 & 0,02 \\
\hline & Price & Marital status & 2,07 & 0,04 & 0,01 \\
\hline & Financing options & Age of children & 2,45 & 0,01 & 0,02 \\
\hline
\end{tabular}

The duration of marriage for married couples is found to have a wide impact, affecting parental perceptions in information search and final decision stages, price frames setting and retailer choice sub-decisions, as well as the choices of the attributes floor and exposure. 
Marriage duration over 20 years is connected to significantly lower evaluation of children's influence in the two phases of the decisionmaking process and financial boundaries subdecision. Veterans in cohabitation show similar results in respect to the final stage. Respondents married for between 6 and 19 years assess the impact of their children significantly higher than the other two groups in two cases characterized by low children's influence scores - the choice of retailer and floor of the real estate.

Marriage length below 5 years is linked to statistically significant depreciation of young family members' part in the choice of the exposure attribute. No variations are found based on educational and income level of parents, along with number of children in the family, but their age is connected to statistically significant differences in parental perceptions in the information search and final decision stages, price frames setting subdecision and selection of financing options available for the real estate in consideration. Parents with children below 18 evaluate their influence over the decisions stated above considerably higher compared to families with children above 18. It confines with Lee and Levi's (12) findings that children aged between 8 or 9 to about 15 are most influential. A possible explanation might be that adult children are headed towards their independent life and trying to distinguish themselves from the family of origin and its decisions.

\section{CONCLUSION}

This paper brings insights into the decisionmaking behavior of the Bulgarian family with a focus on the forms and degrees of children's influence through the lens of a real estate purchase. According to parental perceptions, children in the family have moderate indirect influence over the purchase of the real estate. They are found most influential at the final stage of the family decision-making process while they affect very slightly the phase of information search. Lowest influence is detected in the choice of retailer and financial frames setting, but highest in the moment of the purchase choice. Most important role of children is identified in the choices of real estate attributes which are directly connected to the comfort of use (number of rooms, quadrature and floor area), local infrastructure (district) and the additional time, efforts and expenses necessary for the family to start the exploitation of their real property (completion of the building).

As a whole, a similar evaluation of children's influence is reported by mothers and fathers. The present study results basically support previous research in the field of children's influence over real estate purchases but oppose to results derived in the context of different product categories. The role of children in this consumer context does not vary between married and cohabiting couples.

Although this paper brings some light to the role of children in a real estate purchase, further development of family decision-making behavior research is necessary to fill a considerable gap in theoretical and practical aspects. The inferences presented in this paper provide a solid basis for future studies in this field with respect to real estate and other product categories. Comparison between parental and children's perceptions on their role in a family decision-making process would add valuable perspectives on family consumer behavior. Future studies aimed at international and intercultural comparative studies in this context have the potential to find wide practical implications. Enriching the scope of research with alternative family types, including parents with different gender orientation will help researchers and real estate marketing specialists keep pace with the dynamic social changes being witnessed nowadays.

\section{REFERENCES}

1. Maclennan, D., The review of Scotland's cities. Edinburgh: Her Majesty's Stationery Office. 2002.

2. Duvall, E. M. and Miller, B. C., Marriage and family development - 6th edition. New York: Harper and Row, 1985.

3. Spiro, R. L., Persuasion in family decisionmaking. Journal of Consumer Research, 9:393-402, 1983.

4. Pettersson, A., Olson, U. and Fjellström, C., Family life in grocery stores - a study of interaction between adults and children. International Journal of Consumer Studies, 28:263-272, 2004.

5. Mikkelsen, M. and Norgaard, M., Children's Influence on Family Decision-Making in Food Buying and Consumption. Young Consumers, 8:197-216, 2007.

6. Yang, S., Zhao, Y., Erdem, T. and Zhao, Y., Modeling the intrahousehold behavioral interaction. Journal of Marketing Research, 47:470-484, 2010.

7. Decrop, A., Group processes in vacation decision-making. Journal of Travel \& Tourism Marketing, 18:23-36, 2005. 
8. Gram, M., Children as co-decisionmakers in the family? The case of family holidays. Young Consumers, 8:19-28, 2007.

9. Belch, G. E., Belch, M. A. and Ceresino, G., Parental and teenage child influences in family decision making. Journal of Business Research, 13(2 ):163-76, 1985.

10. Chaundry, M. and Gupta, A., Children's influence in family buying process in India. Journal of Young Consumers, 13(2 ):161-175, 2012.

11. Kiriinya, S. N., Determinants of children's influence on family purchase decisions in Kenya. International Journal of Academic Research in Business and Social Sciences, 4(7):325-339, 2014.

12.Lee, C., Levi, D., The influence of family members on housing purchase decisions. Journal of Property Investment \& Finance, 22:320-338, 2004.

13. Beatty, S. E. and Talpade, S., Adolescent influence in family decision making: a replication with extension. Journal of Consumer Research, 21(2 ):332, 1994.

14. Swinyard, W. and Sim, P. C., Perception of children's influence on family decision processes. Journal of Consumer Marketing, 4(1 ):25-38, 1987.

15. Filiatrault, P. and Ritchie, J. R. B., Joint purchasing decisions: acomparison of influence structure in family and couple decision-making units. Journal of Consumer Research, 7(2 ):131-140, 1980.

16. Hempel, D., Family role structure and housing decisions. Advances in Consumer Research, 2:71-80, 1975.

17. Shoham, A., and Dalakas, V., Family consumer decision making in Israel: the role of teens and parents. Journal of Consumer Marketing, 20(3):238-251, 2003.

18. Szybillo, G. and Sosanie, A., Family decision making: husband, wife and children. Advances in Consumer Research, 4:46-49, 1977.

19.Jenkins, R. L., The influence of children in family decision making: parents' perceptions. Advances in Consumer Research, 6:413-418, 1979.

20.Foxman, E. R., Tansuhaj, P. S. and Ekstrom, K. M., Family members' perceptions of adolescents' influence in family decision making. Journal of Consumer Research, 15(4):482-491, 1989.

21.Darley, W. F. and Lim, J. S., Family decision making in leisure time activities: an exploratory investigation of the impact of locus of control, child age influence factor

\section{KANCHEVA I.}

and parental type on perceived child influence. Advances in Consumer Research, 13:370-374, 1986.

22. Atkin, C. K., Observation of parent-child interaction in supermarket decision-making. Journal of Marketing, 42(4 ):41-45, 1978.

23. Moschis G. P. and Mitchell L. G., Television advertising and interpersonal influences on adolescents' participation in family consumer decisions. Advanced Consumer Research, 13:314-9, 1986.

24. Flurry, L. A., Children's influence in family decision-making: Examining the impact of the changing American family. Journal of Business Research, 60:322-330, 2007.

25. Wang, S., Holloway, B. B., Beatty, S. E. and Hill, W. W., Adolescent influence in family purchase decisions: an update and cross national extension. Journal of Business Research 60:1117-1124, 2007.

26. Kancheva, I. R., Gender role distribution in residential real estate family decision making. Network Intelligence Studies, 10:123-130, 2017.

27. Davis, H., L., Family decision making as conflict management. Advances in Consumer Research, 1:532-535, 1974.

28. Webster, C., Determinants of marital power in decision making. Advances in Consumer Research, 22:717-722, 1995.

29. Yang, S., Narayan, V. and Assael, H., Estimating the interdependence of television program viewership between spouses: A Bayesian simultaneous equation model. Marketing science, 25:336-349, 2006.

30. Schuptrine, F. K. and Samuelson, G., Dimensions of marital roles in consumer decision making: revisited. Journal of Marketing Research, 13:87-91, 1976.

31. Green, R., Leonardi, J. P., Chandon, J. L., Cunningham, I., Verhage, B., Strazzieri, A., Societal development and family purchasing roles: a cross-national study. Journal of Consumer Research, 9:436-442, 1983.

32. Bello, M.O, Bello V.A., The influence of consumer's behaviour on the variables determining residential property values in Lagos, Nigeria. American Journal of Applied Sciences, 4:774-778, 2007.

33. Andersen, H. S., Explanations for preferences in Denmark for surroundings and location of the home. Urbani Izziv, 22(1):100-114, 2011.

34.Lee, C. and Beatty, S. E., Family structure and influence in family decision making, Journal of Consumer Marketing, 19:24-41, 2002. 